American Journal of Applied Sciences 5 (6): 689-697, 2008

ISSN 1546-9239

(C) 2008 Science Publications

\title{
Gender Differences in the Usage and Attitudes toward the Internet among Student Teachers in a Public Malaysian University
}

\author{
${ }^{1}$ Wong Su Luan, ${ }^{2} \mathrm{Ng}$ Siew Fung and ${ }^{3}$ Hanafi Atan \\ ${ }^{1}$ Department of Science and Technical Education, Faculty of Educational Studies University Putra \\ Malaysia, 43400 Serdang, Selangor, Malaysia \\ ${ }^{2}$ Cheras Secondary School, Jalan Yaacob Latif, \\ 56000 Kuala Lumpur, Wilayah Persekutuan, Malaysia \\ ${ }^{3}$ School of Distance Education, Universiti Sains Malaysia, \\ 11800 Penang, Malaysia
}

\begin{abstract}
The problems of gender disparity in the usage and attitude towards the Internet have received considerable interest among researchers. Most findings have revealed that females are at a disadvantage compared to their male counterparts where Internet usage is concerned. They have unequal access, a low rate of usage and exhibit negative attitudes towards the Internet (Nachmias et al., 2000; Sherman et al., 2000; Madell \& Muncer, 2004). Prompted by these observations, this study was carried out to investigate the gender disparity in Internet usage and the attitudes among 152 student teachers (80 females and 72 males) at a public Malaysian university (Universiti Putra Malaysia). The results of this study revealed no gender disparity in Internet usage; the female student teachers were found to spend as much time using the Internet as their male counterparts. These results accordingly contradicted the common findings of other researchers. The results also revealed that the students exhibited positive attitudes toward the Internet regardless of gender, again in contradiction to most other findings. Possible reasons and the implications of these findings will be elaborated and discussed.
\end{abstract}

Key words: Internet attitudes; Internet use; gender differences; gender similarities, gender gap, Internet functionalities

\section{INTRODUCTION}

The advancement of Information and Communication Technology (ICT) and, in particular the Internet, has altered the way education is being delivered. The Internet provides a limitless source of information and with the array of instructional tools available, it has the capability of enhancing and facilitating learning at all levels of education ${ }^{[1]}$. Given the current prevalence of usage of the Internet in education, it is imperative for teachers to acquire the relevant skills to use the Internet, as well as acquire the right attitude for the purpose of classroom instruction. The skilful use of the Internet and the right attitude ensure that teachers will make the right selection of relevant and appropriate information for their students $^{[2]}$. Shelly, Cashman, Gunter and Gunter ${ }^{[3]}$ further added that teachers also need to know how to integrate technology, particularly the Internet, to promote an active learning and authentic learning environment. This new environment provides a new dimension in teaching as the instructors are now required to be facilitators in learning, act as content experts as well as be competent in the use of the Internet $^{[4]}$.

Realising the need for teachers to be proficient and skilful in the usage of the Internet for classroom instruction, all teacher training programmes in Malaysia have been designed to incorporate at least one compulsory discrete Information Technology (IT) course. This move was in part a response to the Malaysian Ministry of Higher Education's (MOHE) directive in 2003 to all curriculum planners for the teacher training programmes provided at the institutions of higher learning throughout Malaysia. Such incorporation aims at inculcating in student teachers the appropriate IT culture and to facilitate the flow of information and the management of knowledge,

Corresponding Author: Wong Su Luan, Department of Science and Technical Education, Faculty of Educational Studies, Universiti Putra Malaysia, 43400 Serdang, Selangor, Malaysia 
problem solving techniques and innovation in teaching as well as in decision making processes ${ }^{[5]}$. As IT and particularly the Internet have become an important part of the Malaysian teacher education curriculum, research to elucidate the extent to which student teachers use the Internet and the way they react to this technology is appropriate and necessary.

Gender and the Internet: As widespread use of, and dependency on, the Internet increase especially in education, it was found that not everyone has equal opportunities to its access and usage ${ }^{[6]}$. It is certainly a cause for concern as it is a part of the digital divide problem. Factors such as income, the educational level, class, gender, race and geographical location have been attributed to this disparity ${ }^{[7]}$. Of all these factors, the gender issues have gained the uttermost attention among researchers and this is evident in many studies conducted as early as in the $1990 \mathrm{~s}^{[8,9,10]}$.

Many of the arguments underlying gender disparities in online use and access stem from gender disparities in computer access and usage ${ }^{[11,12,13]}$. Many of these studies indicated that Internet access and usage have mainly been dominated by males. The study by Nachmias, Mioduser and Shemla ${ }^{[14]}$ suggested that gender differences exist in the use of the Internet with a higher and more extensive usage by males when compared to females. Males are also found to spend more of their time on the Internet, indicating preferred locations for use, resource downloading, website creation and participation in discussion groups. A study by Madell and Muncer ${ }^{[15]}$ and Sherman et al. ${ }^{[16]}$ supported the bias towards males. More males tend to use the World Wide Web; they are also more likely to have their own e-mail addresses and web pages and spend longer hours than females surfing the Internet. Sherman et al. ${ }^{[16]}$ further reported that males, other than for e-mail, used the technology more often and had more positive attitudes than females. The bias is seen even though both girls and boys are equally comfortable and show positive feelings toward the Internet.

Most studies indicated male domination in terms of usage of, and attitude towards, the Internet; fewer studies showed otherwise. A study by Shaw and Gant ${ }^{[17]}$ showed that no gender differences are detected when participants are involved in various online activities such as synchronous and dyadic chat sessions. Odell et al. ${ }^{[18]}$ had obtained similar findings that gender is not a significant variable in terms of Internet use.
The status of gender gap among student teachers in Malaysia remains unclear. Student teachers whose ages range between 20 and 24 years old are well within the age range of users identified as one of the biggest groups of Internet users in Malaysia. For that reason, we feel that there is a need to understand how they use and react towards the Internet. The main focus of this paper, therefore, is to elucidate the gender differences in student teachers' use of, and attitudes toward, the Internet. In undertaking this research the following research questions were asked:

- Are there any differences in terms of time spent on the Internet between genders?

- Are there any differences in the types of Internet functionalities used by female and male student teachers?

- Are there any differences in the female and male student teachers' attitudes toward the Internet?

\section{MATERIALS AND METHODS}

Participants: The sample for this study were 152 student teachers enrolled at the Faculty of Educational Studies, Universiti Putra Malaysia (UPM) comprising 80 females and 72 males. The mean age was 22.55

$(\mathrm{SD}=3.86)$ for the females and $22.49(\mathrm{SD}=3.93)$ for the males; there was no significant difference between the mean age of both groups $[\mathrm{t}(150)=-0.101, \mathrm{p}=$ 0.92]. All participants had prior experience using the Internet. The mean years of Internet experience was 2.54 years $(\mathrm{SD}=1.59)$ for the females and 2.62 years $(\mathrm{SD}=1.16)$ for the males and there was no significant difference between them $[\mathrm{t}(150)=-0.371, \mathrm{p}=0.71]$.

Instrumentation, validation and pilot test: The instrument developed for this study was in the national language (Malay Language). The instrument developed to measure the attitudes was adapted from Tsai, Lin and $\mathrm{Tsai}^{[19]}$ and consisted of fifteen items. Each item was accompanied by a five point Likert-type scale ranging from strongly disagree (5) to strongly agree (1) The sub-scales that made up the attitude construct were perceived usefulness, emotional response and perceived control. In this study, perceived usefulness was defined as student teachers' perception of the positive impacts of the Internet on society and the individual, emotional response was defined as the student teachers' feelings and anxiety when using the Internet and perceived 
control was defined as student teachers' confidence of the independent control of the Internet ${ }^{[19]}$. The justification for measuring these three sub-scales for attitudes was also based on Liaw's ${ }^{[20]}$ view that user attitudes toward computer and Internet technologies can be divided into three primary measurements: affective, cognitive and behavioral measurements. According to Liaw ${ }^{[20]}$, the affective measurement (such as emotional response towards the Internet) and the cognitive measurement (such as perceived usefulness of the Internet) have a positive effect on the behavioural measurement (such as perceived control of the Internet) [21].

The items measuring the Internet usage consisted of eleven different types of Internet functionalities. Several of these items were adapted from the instrument developed by Hills and Argyle ${ }^{[22]}$. Participants were required to indicate their frequency of usage for each of these functionalities. A five Point Likert-type scale corresponding to never, rarely, sometimes, frequently and very frequently, accompanied each item. In this study, rarely meant an average Internet usage of 15 minutes per day, sometimes indicated an average Internet usage of between 15 minutes to 1 hour per day, frequently meant an average usage of between 1 to 3 hours per day and very frequently indicated an average usage of more than 3 hours per day. The eleven functionalities were grouped into three main categories, namely, the information, social and leisure categories. The Internet is a potential source of knowledge, information as well as a platform for social interaction. As such, Internet usage is usually motive driven -- mainly for the three aspects of communication, information gathering and entertainment ${ }^{[17]}$.

Two of the authors of this paper content validated all the items in the questionnaire. The items were also checked for clarity. The item "The Internet can allow me to do more interesting and imaginative work" was changed to "The Internet can allow me to do more imaginative work" because it was double barreled in nature. A qualified person with vast experience in the field of computer technology but not involved in the research was also asked to validate the items. All three content validators found the items to be suitable in the Malaysian context.

A double back translation was carried out on items to ensure that the items in the Malay Language were equivalent to the original English version. Three bilingual schoolteachers were involved in the translation process. The first teacher translated the original English version into Malay. The second teacher then retranslated the Malay version into English without looking at the original version. Finally, the third teacher compared the original and the translated English versions. The teacher agreed that the meanings of both versions were consistent.

The instrument was pilot tested on a group of student teachers from the same university who were not included in the actual study. Twenty-nine out of thirty respondents answered the items fully. Of the 29 respondents, seven were males. The Cronbach alphas recorded for sections measuring Internet use and attitudes were 0.62 and 0.77 , respectively.

One of the authors of this paper collected the data for the pilot test at the beginning of a lecture with the prior permission of the course instructor. The same author was present throughout the data collection process to entertain any queries from the participants. There were, however, no queries suggesting that the items were clear and comprehensible.

The internal consistency of the final version of the instrument was ascertained through the Cronbach alpha coefficients. The Cronbach alpha coefficients for items measuring Internet use and attitudes toward the Internet were recorded at 0.78 and 0.77 , respectively. These values were considered high as they exceeded the minimal consistency guidelines (>.70) recommended by DeVellis ${ }^{[18]}$.

Instrumentation, validation and pilot test: The instrument developed for this study was in the national language (Malay Language). The instrument developed to measure the attitudes was adapted from Tsai, Lin and Tsai ${ }^{[19]}$ and consisted of fifteen items. Each item was accompanied by a five point Likert-type scale ranging from strongly disagree (5) to strongly agree (1). The sub-scales that made up the attitude construct were perceived usefulness, emotional response and perceived control. In this study, perceived usefulness was defined as student teachers' perception of the positive impacts of the Internet on society and the individual, emotional response was defined as the student teachers' feelings and anxiety when using the Internet and perceived control was defined as student teachers' confidence of the independent control of the Internet ${ }^{[19]}$. The justification for measuring these three sub-scales for attitudes was also based on Liaw's ${ }^{[20]}$ view that user attitudes toward computer and Internet technologies can be divided into three primary measurements: affective, 
cognitive and behavioral measurements. According to Liaw $^{[20]}$, the affective measurement (such as emotional response towards the Internet) and the cognitive measurement (such as perceived usefulness of the Internet) have a positive effect on the behavioural measurement (such as perceived control of the Internet) [21].

The items measuring the Internet usage consisted of eleven different types of Internet functionalities. Several of these items were adapted from the instrument developed by Hills and Argyle ${ }^{[22]}$. Participants were required to indicate their frequency of usage for each of these functionalities. A five Point Likert-type scale corresponding to never, rarely, sometimes, frequently and very frequently, accompanied each item. In this study, rarely meant an average Internet usage of 15 minutes per day, sometimes indicated an average Internet usage of between 15 minutes to 1 hour per day, frequently meant an average usage of between 1 to 3 hours per day and very frequently indicated an average usage of more than 3 hours per day. The eleven functionalities were grouped into three main categories, namely, the information, social and leisure categories. The Internet is a potential source of knowledge, information as well as a platform for social interaction. As such, Internet usage is usually motive driven-mainly for the three aspects of communication, information gathering and entertainment $^{[17]}$.

Two of the authors of this paper content validated all the items in the questionnaire. The items were also checked for clarity. The item "The Internet can allow me to do more interesting and imaginative work" was changed to "The Internet can allow me to do more imaginative work" because it was double barreled in nature. A qualified person with vast experience in the field of computer technology but not involved in the research was also asked to validate the items. All three content validators found the items to be suitable in the Malaysian context.

A double back translation was carried out on items to ensure that the items in the Malay Language were equivalent to the original English version. Three bilingual schoolteachers were involved in the translation process. The first teacher translated the original English version into Malay. The second teacher then retranslated the Malay version into English without looking at the original version. Finally, the third teacher compared the original and the translated
English versions. The teacher agreed that the meanings of both versions were consistent.

The instrument was pilot tested on a group of student teachers from the same university who were not included in the actual study. Twenty-nine out of thirty respondents answered the items fully. Of the 29 respondents, seven were males. The Cronbach alphas recorded for sections measuring Internet use and attitudes were 0.62 and 0.77 , respectively.

One of the authors of this paper collected the data for the pilot test at the beginning of a lecture with the prior permission of the course instructor. The same author was present throughout the data collection process to entertain any queries from the participants. There were, however, no queries suggesting that the items were clear and comprehensible.

The internal consistency of the final version of the instrument was ascertained through the Cronbach alpha coefficients. The Cronbach alpha coefficients for items measuring Internet use and attitudes toward the Internet were recorded at 0.78 and $0, .77$ respectively. These values were considered high as they exceeded the minimal consistency guidelines (>.70) recommended by DeVellis ${ }^{[18]}$.

\section{RESULTS}

Time Spent on the Internet: Table 1 shows the means and standard deviations of the time spent on the Internet per week for both genders in two sub-categories, namely, Internet access and the absence of Internet access at home. When Internet access is concerned, it appeared that males spent more time on the Internet than females. In-depth analysis revealed that there were several extreme users from both genders. The distributions of average hours of Internet usage were skewed for both groups; hence the medians were computed and the Mann-Whitney test performed. The Mann-Whitney test showed no significant differences between genders in terms of the median hours they spent on Internet usage (Mann Whitney = 2862.00; $\mathrm{p}=0.95)$. When these data were split between those with and without the Internet access, no significant differences were detected between females and males with Internet access at home (Mann Whitney = 365.50; $\mathrm{p}=0.45)$ and between females and males without Internet access at home (Mann Whitney $=1062.50 ; \mathrm{p}=$ $0.74)$. 
Am. J. Applied Sci., 5 (6): 689-697, 2008

Table 1: Mean time spent on the Internet according to gender

\begin{tabular}{|c|c|c|c|c|c|c|c|c|c|c|c|}
\hline & & & & & Female & & & & & & \\
\hline & & & & Wit & nnet & Wi & nternet & $\mathrm{Wi}$ & & $\mathrm{Wi}$ & ternet \\
\hline $\mathrm{N}$ & Mean & $\mathrm{N}$ & Mean & $\mathrm{N}$ & Mean & $\mathrm{N}$ & Mean & $\mathrm{N}$ & Mean & $\mathrm{N}$ & Mean \\
\hline & (SD) & & (SD) & & (SD) & & (SD) & & (SD) & & (SD) \\
\hline & hour & & hour & & hour & & hour & & hour & & hour \\
\hline 80 & $\begin{array}{l}3.20 \\
(2.68)\end{array}$ & 72 & $\begin{array}{l}3.74 \\
(4.64)\end{array}$ & 33 & $\begin{array}{l}3.27 \\
(2.08)\end{array}$ & 47 & $\begin{array}{l}3.15 \\
(3.06)\end{array}$ & 25 & $\begin{array}{l}5.32 \\
(7.00)\end{array}$ & 47 & $\begin{array}{l}2.89 \\
(2.36)\end{array}$ \\
\hline
\end{tabular}

Table 2: The usage of the Internet functionalities between genders

\begin{tabular}{|c|c|c|c|c|}
\hline \multirow[b]{2}{*}{ Services } & \multicolumn{2}{|l|}{ Females } & \multicolumn{2}{|l|}{ Males } \\
\hline & $\begin{array}{l}\text { Mean } \\
\text { frequency of } \\
\text { use }\end{array}$ & $\begin{array}{l}\mathrm{SD} \\
\text { frequency of } \\
\text { use }\end{array}$ & Mean & SD \\
\hline E-mail to friends ${ }^{\mathrm{s}}$ & 2.69 & 1.09 & 2.15 & 0.96 \\
\hline E-mail to family ${ }^{\mathrm{s}}$ & 1.63 & 0.92 & 1.53 & 0.77 \\
\hline Getting information in general ${ }^{\mathrm{i}}$ & 3.79 & 0.95 & 3.38 & 1.07 \\
\hline E-mail for studies ${ }^{\mathrm{i}}$ & 2.97 & 1.11 & 2.81 & 1.12 \\
\hline Getting information for studies ${ }^{\mathrm{i}}$ & 3.89 & 0.87 & 3.44 & 1.07 \\
\hline Online bankings & 1.29 & 0.79 & 1.26 & 0.63 \\
\hline Online shopping ${ }^{\mathrm{s}}$ & 1.10 & 0.44 & 1.11 & 0.46 \\
\hline Downloading free software $^{s}$ & 2.44 & 1.09 & 2.28 & 1.30 \\
\hline Accessing online newspapers ${ }^{\mathrm{i}}$ & 2.17 & 1.11 & 1.92 & 1.12 \\
\hline Online discussion $^{1}$ & 1.73 & 1.10 & 1.69 & 1.08 \\
\hline Online games ${ }^{1}$ & 1.81 & 1.07 & 1.96 & 0.99 \\
\hline
\end{tabular}

Preferences of Internet Functionalities: Table 2 shows that both female and male participants used the Internet mostly for information related purposes as indicated by the high means (> 3.00). The online information sought by both genders was mainly for academic purposes. As indicated by the low means $(<1.30)$, the two least favoured activities for bot females and males were online shopping and banking. The results seemed to suggest that female and male participants tended to use the Internet to access information and socialising facilities using the Internet communications tools. It also showed that both genders treated the Internet as a useful learning tool and used it frequently to gather information related to their learning tasks.

A multivariate analysis of variance (MANOVA) was performed to investigate if gender (independent variable) differences existed in terms of the Internet preferences on the functionalities (the dependent variable). Internet preferences on the functionalities were categorised into social, information and leisure factors. Preliminary assumption testing was conducted to check for normality, linearity, univariate and multivariate outliers, homogeneity of variancecovariance matrices and multicollinearity. No serious violation was noted except for the equality of variance
Table 3.: Mean scores for types of Internet use according to gender

\begin{tabular}{lllll}
\hline & \multicolumn{2}{c}{ Female } & \multicolumn{2}{c}{ Male } \\
$\begin{array}{llll}\text { Dependent } \\
\text { variables }\end{array}$ & Mean & S.D. & Mean & S.D. \\
\hline Social & 9.13 & 2.68 & 8.33 & 2.73 \\
Information & 12.83 & 2.84 & 11.54 & 3.28 \\
Leisure & 3.54 & 1.92 & 3.65 & 1.79 \\
\hline
\end{tabular}

for the dependent variable (information) which was not met. Pallant ${ }^{[23]}$ suggested that if this assumption was violated, a more conservative alpha level to determine the significance for that variable had to be used. Tabachnick and Fidell ${ }^{[24]}$ recommended an alpha of 0.025 or 0.01 . In this analysis, we decided to use the most stringent alpha level of 0.01 because of the aforesaid violation.

The analysis revealed that there was no statistical significant difference between genders on the combined dependent variables: $F(3,148)=4.564, P=0.03$; Pillai's Trace $=.058$, partial eta squared $=.058$. This suggested that the means on the dependent variables were the same for the three types of Internet functionalities (information, socialisation and leisure). In other words, female preferences towards the Internet functionalities were comparable with male preferences. Both genders preferred to use the Internet mainly for accessing information rather than for socialising or 
Table 4: Attitudes toward the Internet according to gender

\begin{tabular}{|c|c|c|c|c|c|}
\hline & \multirow[b]{2}{*}{ Items } & \multicolumn{2}{|c|}{ Females } & \multicolumn{2}{|l|}{ Males } \\
\hline & & Mean & SD & Mean & SD \\
\hline 1 & I could probably teach myself most of the things I need to know about the Internet ${ }^{c}$ & 1.94 & 0.70 & 1.81 & 0.73 \\
\hline 2 & I hesitate using the Internet in case I look stupid*a & 1.41 & 0.72 & 1.50 & 0.71 \\
\hline 3 & The Internet can allow me to do more imaginative work ${ }^{u}$ & 2.38 & 0.96 & 2.37 & 0.88 \\
\hline 4 & I need an experienced person nearby when I use the Internet ${ }^{*}$ & 2.94 & 1.22 & 3.28 & 1.15 \\
\hline 5 & If given the opportunity to use the Internet, I am afraid that I might damage it in some way*c & 2.31 & 1.09 & 2.54 & 1.17 \\
\hline 6 & The Internet makes society more advanced ${ }^{\mathrm{u}}$ & 1.68 & 0.91 & 1.51 & 0.67 \\
\hline 7 & The Internet makes me feel uncomfortable $*^{\mathrm{a}}$ & 1.86 & 0.79 & 1.92 & 0.85 \\
\hline 8 & The Internet enlarges my scope ${ }^{u}$ & 1.50 & 0.76 & 1.50 & 0.61 \\
\hline 9 & I do not need someone to tell me the best way to use the Internet ${ }^{c}$ & 3.65 & 0.86 & 3.63 & 0.99 \\
\hline 10 & I feel bored toward using the Internet ${ }^{* a}$ & 2.06 & 0.88 & 2.04 & 0.68 \\
\hline 11 & The Internet makes a great contribution to human life ${ }^{u}$ & 1.80 & 0.88 & 1.75 & 0.75 \\
\hline 12 & I can use the Internet independently, without the assistance of others ${ }^{\mathrm{c}}$ & 2.29 & 0.83 & 2.51 & 1.10 \\
\hline 13 & When using the Internet, I am not quite confident about what I am doing $*^{\mathrm{a}}$ & 2.44 & 0.91 & 2.47 & 0.96 \\
\hline 14 & The Internet helps me acquire relevant information I need ${ }^{\mathrm{u}}$ & 1.83 & 0.71 & 1.96 & 0.72 \\
\hline 15 & If I get problems using the Internet, I can usually solve them one way or the other ${ }^{c}$ & 2.30 & 0.82 & 2.21 & 0.79 \\
\hline
\end{tabular}

Table 5: .Mean scores for attitudes according to gender

\begin{tabular}{lllll}
\hline & \multicolumn{2}{c}{ Female } & \multicolumn{2}{c}{ Male } \\
& - Mean & S.D. & Mean & S.D. \\
\hline Dependent variables & 9.62 & 2.34 & 9.79 & 2.07 \\
Perceived usefulness & 9.89 & 2.78 & 10.47 & 2.99 \\
Emotional response & 12.41 & 2.39 & 12.74 & 2.64 \\
Perceived control & & & &
\end{tabular}

leisure purposes. Table 3 illustrates the means and standard deviations for each of the three functionalities according to gender.

Attitudes toward the Internet: Table 4 depicts the mean scores of all the items regarding the attitudes toward the Internet according to gender. The lower mean scores corresponded to attitudes that were more positive because of the reverse scoring used. The items with mean scores below 2.00 for both genders were items nos. 1, 2, 6, 7, 8, 11, and 14. From these seven items, four items were from the construct of usefulness. This suggested that both genders were aware of the benefits of the Internet and were willing to use it as a tool when undertaking important tasks. Both genders strongly disagreed on the opinions that they hesitated and felt uncomfortable using the Internet. On the whole, although both genders shared the seven lowest mean scores, the mean scores for females being slightly lower than those achieved by males.

The items were also summed up according to the three attitude constructs: perceived: usefulness, emotional response and perceived control. Table 5 presents the participants' mean scores on these three sub-scales according to gender. Both females and males scored the lowest on the emotional response sub-scale followed by perceived usefulness and lastly, the perceived control sub-scale. This suggested that both groups perceived the Internet as useful and exhibited positive feelings towards the technology. However, the results indicated that they did not perceive themselves to be in control when using the Internet. This means that they possibly lacked skills when navigating through the technology and needed assistance when using its various functionalities.

MANOVA was also performed to investigate gender differences in attitudes toward the Internet. The three dependent variables of the attitudes were the perceived usefulness, perceived control and emotional response. The testing of the preliminary assumption was again conducted to check for normality, linearity, univariate and multivariate outliers, homogeneity of variance-covariance matrices and multicollinearity. No serious violation was noted except that the presence of multivariate outliers was detected, suggesting that one or more cases exceeded the critical value (16.27) of Mahalanobis distance. It was found that one case had far exceeded this value. Based on Pallant's (2001) recommendation, we decided to remove this case from the sample and analysis was tested at the alpha level of .01 . The analysis revealed that there was no statistical significant difference between genders for attitudes: $\mathrm{F}(3,147)=0.517, \mathrm{P}=0.02$; pillai's Trace $=0.010$, partial eta squared $=.010$. This suggested that the means for the scores of dependent variables (perceived usefulness, emotional response and perceived control dimensions) were the same for student teachers in both groups. 


\section{DISCUSSION}

The purpose of this research was to investigate the extent of gender differences on student teachers' use and attitudes toward the Internet. The sample was homogenous in terms of age and prior Internet experience; hence, the effects from these elements towards the results and analyses were considered marginal and not significant. For that reason, the mediating effects of age and Internet experience on gender as suggested by Weiser ${ }^{[25]}$ were not considered as a threat in this research.

The results revealed that the amount of time that the females students spent accessing the Internet were the same as that of their male counterparts. There were no gender differences detected between them. This was also true in the situation where the respondents were with or without access to the Internet at home. The results reflected that the gender gap in Internet usage among the respondents was marginal and almost nonexistent and females in this study spent as much time on the Internet as their male counterparts. The results of this study were consistent with the earlier findings of Odell et al. ${ }^{[18]}$ and Shaw and Gant ${ }^{[17]}$. They reported that the gender gap in the use of the Internet has been narrowing in recent years.

The results also revealed that regardless of gender, almost all the participants used the Internet to search for information, mainly for educational purposes. This indicated that the most popular Internet functionalities used and sought by the respondents in this study were related to education. This is expected as the respondents were university students and their search in the Internet would have been related to the fulfillment of their educational tasks. Duggan et al. ${ }^{[26]}$ also reported that university students usually used the Internet for term paper research, retrieval of course notes and spent longer hours on these functionalities compared to others. However, this result was in contradiction to the findings of Odell et al. ${ }^{[18]}$ and Weiser ${ }^{[25]}$ which reported a gender discrepancy in the usage of Internet for educational purposes with females being more likely to use these functionalities compared to their male counterparts. Apart from educational purposes, both genders also perceived that the Internet was a useful tool for many other purposes with no differences between gender in the perception in this category. They also regarded the Internet as a tool for seeking entertainment and socialising but used it for those purposes less frequently than when there existed an educational purpose.

In terms of the communication functionalities, the use of the e-mail for their studies was the most preferred by both genders and they used these functionalities mostly for educational purposes, followed by a much lesser extent for socialising and leisure. Again, being students played a significant contribution towards these preferences as they were expected to give priority to activities related to information retrieval for educational purposes rather than for social or leisure purposes. The results concurred well with the results reported by Ramayah, Muhamad and Bushra ${ }^{[27]}$ that students used the Internet mainly for seeking information related to educational purposes. This, however, contrasted with the findings of Mathews and Schrum ${ }^{[28]}$ who reported that students in the USA spent less time using the Internet for academic purposes as compared to non-academic matters.

The scores on the perceived usefulness and perceived control sub-scales for both genders did not arrive at any statistical differences. It seemed that both genders perceived similar levels of usefulness of the Internet but they were somewhat lacking in the required skills when using it. In other words, these students may prefer to have someone more experienced to provide guidance to them. The data also revealed that no gender differences existed for the emotional response sub-scale where females and males shared the same feelings when using the Internet. The moderate emotional response mean scores for both genders were indicative that they were likely to be less anxious about future use of the Internet as well.

Indeed, previous studies ${ }^{[20,29,30]}$ indicated that there was a significant gender difference in the attitudes toward the Internet where males were more likely to have more positive feelings toward the technology than females. This study, however, did not lend any support to these results but instead; it offered some evidence that the gender gap in attitudes towards the Internet was diminishing.

There are possibilities that the lack of gender differences could possibly be attributed to the sample being studied. The participants involved in this study were students of a public university in Malaysia. They were likely to posses some experience in using the Internet. This is particularly so because they had taken the compulsory IT introductory course earlier in the first semester of their study. Part of the course exposed them to a six-hour hands-on laboratory session on the 
Internet where they were taught how to create a simple homepage, upload their homepage to the World Wide Web, register for an e-mail account and use a search engine. This Internet exposure prior to the study might have contributed to the similarity between the genders as observed in the results. Additionally, the university has continued to upgrade the Internet infrastructure to enhance Internet accessibility around the campus, making these services readily available to all students. With the improved facilities, both females and males have equal access and opportunities to use the Internet with no disparity between them.

\section{LIMITATIONS OF THE STUDY}

It should be noted that this study was exploratory in nature. All data collected were based entirely on the honesty and how the participants perceived their Internet usage and attitudes toward the Internet. This study only involved student teachers from one public university in Malaysia. Therefore, caution must be taken when generalizing any findings for the entire population of student teachers in Malaysia. Apart from the reasons stated above, the generalisability of this study is also limited as the conclusions are based on the evidence from this particular study, where the participants possessed moderate level of prior Internet experience $(M=2.54$; S.D.=1.59). Further research is, therefore, needed to include participants with higher or lower prior Internet experience as the results may change under such circumstances.

\section{REFERENCES}

1. Poole, B.J. 1997. Education for an Information Age. New York: McGraw-Hill.

2. Sharp, V. 2001. Computer Education for Teachers: Integrating Technology into Classroom Teaching. Boston: McGraw Hill.

3. Shelly, G.B., T.J. Cashman, R.E. Gunter, and G.A. Gunter, 2004. Teachers Discovering Computers-Integrating Technology into the Classroom. Boston, Massachusetts: Thomson Course Technology.

4. Anderson, D.K. and W.M. Reed, 1998. The effects of Internet instruction, prior computer experience, and learning style on teachers' Internet attitudes and knowledge. Journal of Educational Computing Research, 19 (3): 227-246.
5. Quality Assurance Unit 2003. Guidelines on Criteria and Standards for Programmes in the Field of Education. Putrajaya: Ministry of Higher Education.

6. Papastergiou, M. and C. Solomonidou, 2005. Gender issues in Internet access and favourite Internet activities among Greek high school pupils inside and outside school. Computers \& Education, 44(4): 377-393.

7. Norris, P. 2001. Digital Divide: Civic Engagement, Information Poverty, and the Internet Worldwide. New York: Cambridge University Press.

8. Matheson, K. and M.P. Zanna. 1990. Computermediated communications: the focus is on me. Social Science Computer Review, 8: 1-12.

9. Cardman, E.R. 1990. The gender gap in computer use: implications for bibliographic instruction. Research Strategies, 8, 116-128.

10. Allen, B. 1995. Gender and computer-mediated communication. Sex Roles, 32(7/8): 557-563.

11. Lockheed, M.E. (1985). Women, girls and computers: A first look at the evidence. Sex Roles, 13: $115-122$.

12. Hawkins, J. 1985. Computers and girls: rethinking the issues. Sex Roles, 13: 165-180.

13. Rakow, L.F. 1988. Gendered technology, gendered practice. Critical Studies in Mass Communication, 5: 57-70.

14. Nachmias, R., D. Mioduser and A. Shemla, (2000). Internet usage by students in an Israeli high school. Journal of Educational Computing Research, 22: 55-73.

15. Madell, D. and S. Muncer. 2004. Gender differences in the use of the Internet by English secondary school children. Social Psychology of Education, 7: 229-251

16. Sherman, R.C., C. End, E. Kraan, A. Cole, J. Campbell, Z. Birchmeier and J. Klausner. (2000). The Internet gender gap among college students: forgotten but not gone? CyberPsychology \& Behavior, 3(5): 885-894.

17. Shaw, L. and L. Gant. 2002. Users divided? Exploring the gender gap in Internet use. CyberPsychology \& Behavior, 5(6): 517-527.

18. Odell, P., K. Korgen, P. Schumacher and M. Delucchi. 2000. Internet use among female and male college students. CyberPsychology \& Behavior, 3(5): 855-862.

19. Tsai, C.C., S.J. Lin and M.J. Tsai.. 2001. Developing an Internet attitude scale for high school students. Computers \& Education, 37: 41 51. 
20. Liaw, S.S. and H.M. Huang. 2003. An investigation of users attitudes toward search engines as an information retrieval tool. Computers in Human Behavior, 19(6): 751-765.

21. Hills, P. and M. Argyle. 2003. Uses of the Internet and their relationships with individual differences in personality. Computers in Human Behavior, 19: 59-70.

22. Pallant, J. 2001. SPSS survival manual, Canberra: McPherson.

23. Tabachnick, B.G., and L. S. Fidell, 1996. Using Multivariate Statistic (3rd Ed.). New York: HarperCollins.

24. Weiser, E. 2000. Gender differences in Internet use patterns and Internet applications preferences: a two sample comparison. CyberPsychology \& Behavior, 3(2): 167-178.

25. Duggan, A., B. Hess, D. Morgan, S. Kim, and Wilson, K. 2001. Measuring students' attitudes toward educational use of the Internet. Journal of Educational Computing Research, 25(3): 267-281.
26. Ramayah, T., J. Muhamad, and A. Bushra, 2003. Internet usage among students of institutions of higher learning: the role of motivational variables. Retrieved November $23 \quad 2003$ from www.management.usm.my/Ramayah/Publication\% $\underline{\text { 5CConf29.doc }}$

27. Mathews, D. and L. Schrum. 2003. High-speed Internet use and academic gratifications in the college residence. Internet and Higher Education, 6: 125-144.

28. Durndall, A. and Z. Haag. 2002. Computer self efficacy, computer anxiety, attitudes towards the Internet and reported experience with the Internet, by gender, in an East European sample. Computers in Human Behaviour, 18: 521-535.

29. Sherman, R.C., C. End, E. Kraan, A. Cole, J. Campbell, Z. Birchmeier and J. Klausner. 2000. The Internet gender gap among college students: forgotten but not gone? CyberPsychology and Behavior, 3(5): 885-894. 